\title{
Aquifoliaceae endémicas del Perú
}

\section{Blanca León ${ }^{1,2}$}

${ }^{1}$ Museo de Historia Natural, Av. Arenales 1256, Aptdo 14-0434, Lima 14, Perú

2 Plant Resources Center, University of Texas at Austin, Austin TX 78712 EE.UU.

blanca.leon@mail.utexas.edu

\section{Resumen}

Esta es una de las familias más conspicuas en los bosques pluviales montanos y húmedos de la vertiente oriental. La familia Aquifoliaceae es reconocida en el Perú por 34 especies en el género Ilex (Brako \& Zarucchi, 1993; Ulloa Ulloa et al., 2004), básicamente árboles. En este trabajo reconocemos nueve especies endémicas, casi la mitad de ellas son conocidas solamente en una localidad, y de éstas sólo una ha sido recolectada en el siglo XX. Estos taxones endémicos habitan principalmente las regiones Bosques Muy Húmedos Montanos y Bosques Muy Húmedos Premontanos, entre los 1100 y 3500 m de altitud. Cuatro especies endémicas de llex han sido reportadas en el Sistema Nacional de Áreas Naturales Protegidas por el Estado.

Palabras claves: Aquifoliaceae, Perú, endemismo, plantas endémicas.

\section{Abstract}

This is one of the most conspicuous families in the pluvial and humid forests of the eastern Andean slopes. The Aquifoliaceae are represented in Peru by 34 species in the genus Ilex (Brako \& Zarucchi, 1993; Ulloa Ulloa et al., 2004), mostly trees. Here we recognize nine endemic species, nearly half of which are known from a single locality. Of these, only one species has been collected in the $20^{\text {th }}$ century. These endemic taxa are found mainly in Very Humid Montane and Premontane Forests regions, between 1100 and 3500 m elevation. Four endemic species of Ilex have been reported within Peru's protected areas system.

Keywords: Aquifoliaceae, Ilex, Peru, endemism, endemic plants.
1. Ilex crassifolia Hook., nom. illeg., non Meerb. 1798

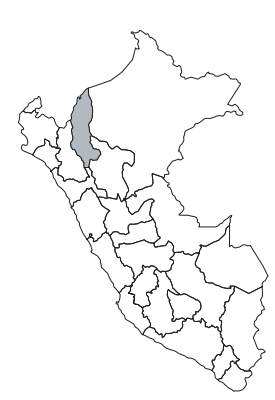

\section{EN, B1ab(iii)} 149. 1837.

Colección tipo: A. Mathews 134

Herbarios: B, BM, K.

Nombre común: Desconocido.

Registro departamental: AM. $2600 \mathrm{~m}$.
Publicación: Icon. Pl. Ind. Orient. 2: t.

Regiones Ecológicas: BMHM; 2300-

SINANPE: PNC

Herbarios peruanos: USM (2).

Observaciones: Árbol conocido de los bosques montanos de subcuencas del Marañón y Pachitea. Esta especie fue descrita de una planta recolectada en el siglo XIX en Amazonas y aparentemente no ha vuelto a ser recolectada en ese Departamento. Amenazas a sus poblaciones fuera de áreas protegidas están asociadas a deforestación e incendios intencionales. El nombre de esta especie requiere un cambio, puesto que fue propuesto con anterioridad para una especie que no es peruana.

\section{Ilex crassifolioides Loes.}

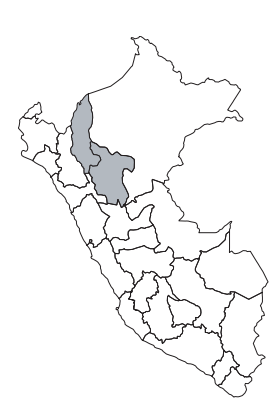

\section{EN, B1ab(iii)}

Publicación: Nov. Act. Acad. Caes. Leop.Carol. Germ. Nat. Cur. 1: 160. 1901.

Colección tipo: R. Spruce 4461

Herbarios: BR, K, W.

Nombre común: Desconocido.

Registro departamental: AM, SM.

Regiones Ecológicas: BMHM; 1600$3350 \mathrm{~m}$.

SINANPE: PNRA

Herbarios peruanos: MOLF (1), USM (3).

Observaciones: Esta especie se conoce del tipo y de tres colecciones recientes. Las localidades más distantes están más de $260 \mathrm{~km}$ aparte. Una población se halla protegida en un parque nacional. Esta especie probablemente sea especialista de bosques maduros.

\section{Ilex gotardensis Loizeau \& Spichiger}

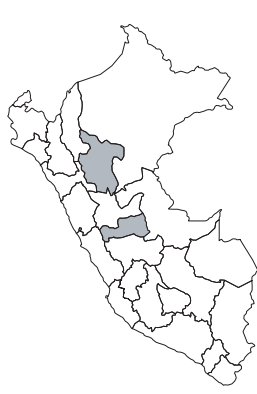

EN, B1ab(iii)

Publicación: Boissiera 48(1): 171, 173174, f. 65. 1994.

Colección tipo: R.B. Foster et al. 7644

Herbarios: G, MO; USM!.

Nombre común: Desconocido.

Registro departamental: PA, SM.

Regiones Ecológicas: BMHM; 2500$3000 \mathrm{~m}$.

SINANPE: PNRA, PNYC

Herbarios peruanos: USM (isotipo+2).

Observaciones: Esta especie se conoce de bosques montanos orientales sobre areniscas. Dos localidades representan poblaciones naturalmente aisladas, si bien su hábitat está afectado por deforestación asociada a quemas.

\section{Ilex jelskii Zahlk.}

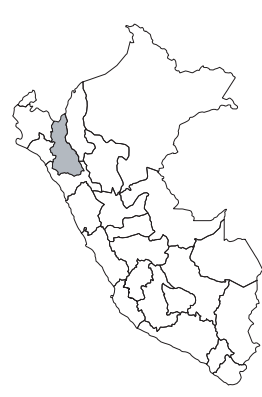

DD

Publicación: Szyszyl., Diagn. Pl. Nov. 1: 9. 1894.

Colección tipo: C. Jelski 37

Herbarios: B.

Nombre común: Desconocido.

Registro departamental: CA.

Regiones Ecológicas: Sin datos; altitud desconocida.

SINANPE: Sin registro.

Herbarios peruanos: Ninguno.

Observaciones: Esta especie arbórea es conocida aparentemente sólo de la colección tipo (Loizeau, 1994), una planta recolectada en 1878, probablemente de los bosques montanos de los alrededores de lo que hoy es el Parque Nacional Cutervo. 


\section{Ilex lilianeae Loizeau \& Spichiger}

$$
\text { CR, B1ab(iii) }
$$

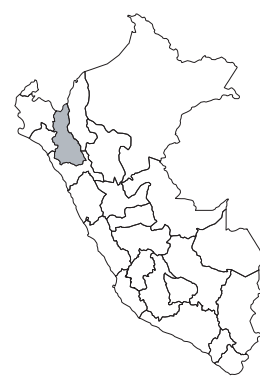

Publicación: Boissiera 48(1): 208. 1994. Colección tipo: D.N. Smith \& I. Sánchez V. 4309

Herbarios: MO.

Nombre común: Desconocido.

Registro departamental: CA.

Regiones Ecológicas: MA; 2700-2900 $\mathrm{m}$.

SINANPE: Sin registro.

Herbarios peruanos: Ninguno.

Observaciones: Arbusto conocido aparentemente sólo de la colección tipo, una planta recolectada en 1983 de una subcuenca del Marañón.

\section{Ilex loretoica Loes.}

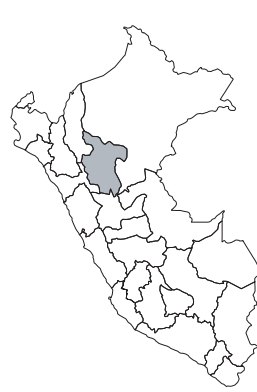

DD

Publicación: Repert. Spec. Nov. Regni Veg. 1: 166. 1905.

Colección tipo: A. Weberbauer 4749

Herbarios: B (d).

Nombre común: Desconocido.

Registro departamental: SM.

Regiones Ecológicas: BMHP; $1500 \mathrm{~m}$.

SINANPE: Sin registro.

Herbarios peruanos: Ninguno.

Observaciones: El único ejemplar que la representa está destruido y no ha permitido interpretar la validez taxonómica de esta especie. La localidad original está ubicada en los alrededores de Moyobamba y al parecer, no ha vuelto a ser recolectada.

\section{Ilex tarapotina Loes.}

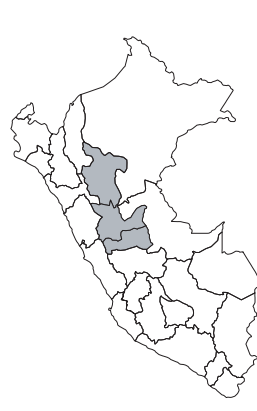

\section{EN, B1a}

Publicación: Nov. Act. Acad. Caes. Leop.Carol. Germ. Nat. Cur. 1: 393. 1901.

Colección tipo: R. Spruce 4399

Herbarios: K, W.

Nombre común: Desconocido.

Registro departamental: HU, PA, SM.

Regiones Ecológicas: BMHP; 1100 $1700 \mathrm{~m}$.

SINANPE: RCS

Herbarios peruanos: USM (4).

Observaciones: Arbusto conocido de tres localidades en el norte y centro de la Amazonía occidental. El ejemplar tipo fue recolectado en el siglo XIX en la cuenca del Mayo. Otras poblaciones son conocidas de las cuencas del Pachitea y Pichis. Una población está en la Reserva Comunal El Sira.
8. Ilex trachyphylla Loes.

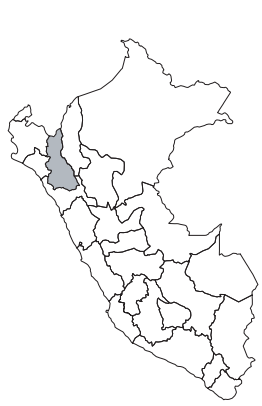

DD

Publicación: Nov. Act. Acad. Caes. Leop.Carol. Germ. Nat. Cur. 2: 277. 1908.

Colección tipo: C. Jelski 1176

Herbarios: B.

Nombre común: Desconocido.

Registro departamental: CA.

Regiones Ecológicas: BMHM; altitud desconocida.

SINANPE: Sin registro.

Herbarios peruanos: Ninguno.

Observaciones: Árbol conocido solamente de la colección tipo, una planta recolectada en el siglo XIX de una localidad en Cajamarca. Aparentemente, esta especie ha sido recolectada en Bolivia, pero este ejemplar disyunto no ha sido verificado. Si se comprobara que se trata de esta especie, entonces no debería incluirsela como un endemismo.

\section{Ilex villosula Loes.}

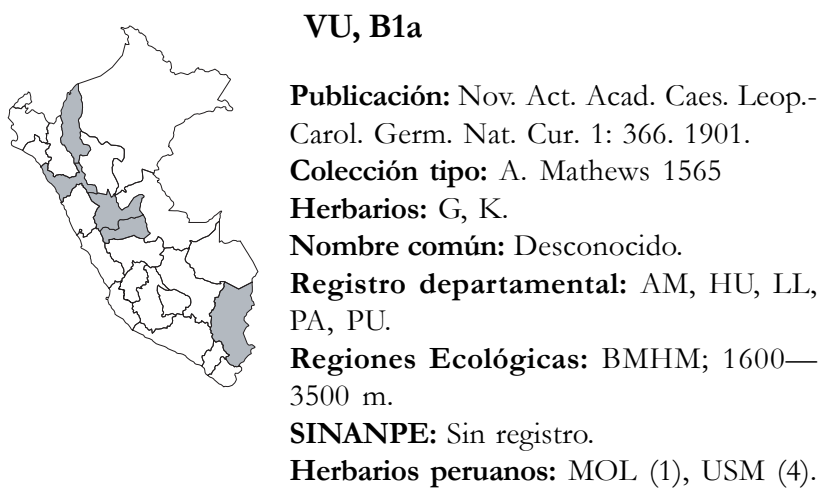

Observaciones: Árbol conocido de varias localidades en la vertiente oriental del país, en las cuencas del Utcubamba y Marañón. Podría estar presente en los países vecinos. 